\title{
ТАКСИС И ВРЕМЕННАЯ ЛОКАЛИЗОВАННОСТЬ: ИНТЕГРАТИВНОЕ МЕЖКАТЕГОРИАЛЬНОЕ ВЗАИМОДЕЙСТВИЕ
}

\section{TAXIS AND TEMPORAL LOCALIZATION: INTEGRATIVE INTER-CATEGORICAL INTERACTION}

\section{Arkhipova}

Summary: The article discusses the functional-semantic categories of taxis and temporal localization in the framework of their integrative intercategorical interaction. In the polycategorical semantical complex, in statements with prepositional deverbatives, the conjugate temporal, iterative, phase-taxis categorical situations of simultaneity and time difference of localized/non-localized in time actions with the multiplicity of subjects/objects and the presence of mono-, bi- or multicomponent explicators (temporal, local, aspectual, iterative, phase, etc.) are actualized.

Keywords: functional-semantic categorical, functional-semantic field, taxis, temporary localization, explicators, polycategorial complex, connected taxis categorical situations.
Архипова Ирина Викторовна

к.филол.н., профессор, Новосибирский государственный педагогический университет

irarch@yandex.ru

Аннотация: В статье рассматриваются функционально-семантические категории таксиса и временной локализованности в рамках их интегративного межкатегориального взаимодействия. В поликатегориальном семантическом комплексе в высказываниях с предложными девербативами актуализируются сопряженные темпорально-, итеративно-, фазово-таксисные категориальные ситуации одновременности и разновременности локализованных/нелокализованных во времени действий при множественности субъектов/объектов и наличии моно-, би- или поликомпонентных экспликаторов (темпоральных, локальных, аспектуальных, итеративных, фазовых и др.).

Ключевые слова: функционально-семантическая категория, функциональносемантическое поле, таксис, временная локализованность, экспликаторы, поликатегориальный комплекс, сопряженные таксисные категориальные ситуации.
$\mathrm{B}$ статье рассматривается вопрос интегративного межкатегориального взаимодействия функционально-семантической категории таксиса и категории временной локализованности/нелокализованности. Функционально-семантическая категория временной локализованности/нелокализованности и средства ее выражения в разноструктурных языках освещаются в работах А.В. Бондарко, И.Н. Смирнова, А.А. Агапитовой, Х.С. Лепшокова, И.Д. Байтувгановой и др. $[1 ; 11 ; 12 ; 13 ; 14 ; 15 ; 18 ; 20 ; 21]$. Временная локализованность/нелокализованность (в дальнейшем - ВЛ/ВНЛ) в обозначаемой ситуации высказывания трактуется как бинарная оппозиция следующих семантических компонентов: 1) конкретности, определенности местоположения действия и ситуации в целом на временной оси, т.е. прикрепленность к какому-то одному моменту или периоду; 2) неконкретности/неопределенности местоположения действия и ситуации на временной оси, т.е. неограниченная повторяемость, обычность (узуальность) или временная обобщенность («вневременность») $[14$, c. $210 ; 1$, c. 3].

Категориальные ситуации временной локализованности/нелокализованности являются выражаемыми различными языковыми средствами типовыми содержательными структурами, базирующимися на семантической категории временной локализованности/ нелокализованности. Семантическая категория вре- менной локализованности/нелокализованности взаимодействует с категорией таксиса и другими функционально-семантическими категориями, объединенными идеей времени (аспектуальности, темпоральности), входя в структуру выделяемого А.В. Бондарко аспектуально-темпорального комплекса [13, с. 96]. С учетом интегративного характера межкатегориального взаимодействия функционально-семантических категорий таксиса, аспектуальности, темпоральности и временной локализованности мы предлагаем использовать термин «темпорально-аспектуально-таксисный поликатегориальный семантический комплекс».

В высказываниях с предложными девербативами, репрезентирующих темпорально-аспектуально-таксисный поликатегориальный семантический комплекс, возможна актуализация двух типов категориальных ситуаций, релевантных в аспекте интегративного взаимодействия категории таксиса и категории ВЛ/НВЛ: 1) конкретных (локализованных во времени); 2) неконкретных (не локализованных во времени, повторяющихся, обычных или так называемых «вневременных»). Категория ВЛ/НВЛ, в отличие от других глагольных категорий, не получает формального выражения средствами морфологии и синтаксиса и представляет, по мнению А.А. Агапитовой, особый тип системно-языкового выражения [1, с. 6]. К языковым средствам репрезентации данной категории, имеющей полевую структуру, относятся разноуровне- 
вые языковые средства (лексические, грамматические, лексико-грамматические). Таковыми являются темпоральные (временные) формы глагола, референтный/ нереферентный субъект, темпоральные и локальные маркеры [1, с. 4]. Кроме того, для актуализации категориальных ситуаций ВЛ/ВНЛ релевантный характер может иметь лексическое и аспектуальная семантика глаголов высказываний.

Категория ВЛ/ВНЛ, рассматриваемая с позиций функциональной грамматики в качестве моноцентрического функционально-семантического поля, находит свою реализацию не только через отношение действий к выражению времени, но и через другие показатели конкретности/неконкретности, в частности, через конкретность/ неконкретность (неопределенность, обобщенность) субъектов и объектов высказывания [14, с. 228-229]. Категория таксиса, рассматриваемая как выражаемая в поли- и полупредикативных высказываниях временная соотнесенность действий в рамках единого временного плана безотносительно к моменту речи, и категория ВЛ/ ВНЛ взаимосвязаны друг с другом и рассматриваются как «близкие друг к другу» или «естественные» функционально-семантические категории.

Категория таксиса трактуется как полицентрическое/ бицентрическое ФСП, формируемое элементами разных языковых уровней (морфологического, лексико-грамматического, синтаксического) $[2 ; 3 ; 4 ; 5 ; 6 ; 7 ; 8 ; 9 ; 10 ; 12 ; 13$; 14]. Семантика временной локализованности/временной нелокализованности действий в высказываниях с предложными девербативами непосредственно связана с таксисно-хронологической семантикой, предполагающей актуализацию различных типов таксисных значений (одновременности, следования, предшествования). Локализованность действий во времени в комплексной ситуации полипропозитивных высказываний является одним из базовых условий актуализации таксисных значений одновременности или разновременности.

При описании комплексного механизма формирования аспектуально-таксисных значений одновременности/разновременности необходимо учитывать особенности всей семантической структуры высказываний: лексическую и аспектуальную семантику глаголов и девербативов, а также такие параметры субъектных и объектных актантов глагольных предикатов, как: одушевленность/неодушевленность, конкретность/ абстрактность, единичность/ множественность и др. В последнем случае категория ВЛ/ВНЛ сопряжена с функционально-семантической категорией аспектуальности, в частности, с субкатегорией итеративности (кратности) в аспекте актуализации таксисных значений дистрибутивной кратности при множественности объектных или субъектных актантов глагольных действий. Синкретич- ный поликатегориальный комплекс содержит различные семантические компоненты, релевантные в аспекте межкатегориального взаимодействия (пересечения, совмещения, синкретизма) и интеграции категории таксиса и временной локализованности/нелокализованности. Они характеризуются разной степенью прототипичности (репрезентативности), «центральности» и регулярности употребления. Семантической доминантой ФСП таксиса являются значения одновременности и разновременности, а семантической константой ФСП ВЛ/ВНЛ - конкретность (локализованность во времени)/ неконкретность (нелокализованность во времени).

К прототипическим семантическим компонентам высказываний, релевантным для актуализации аспектуально-таксисных значений одновременности или разновременности локализованных/нелокализованных во времени действий (процессов, событий), следует отнести следующие:

(1) множественность объектных или субъектных актантов действий: Um sieben Uhr früh grüßten wir einander kaum beim Auseinandergehen ... ; Beim Öffnen rollten zwei große Aktenbündel heraus ... ; Im Stehen zog er diese und jene der kleinen Laden auf ... [23].

Дискретный характер субъектов и объектов действий, который имплицируется множественным числом субъектных или объектных актантов и характеризуется дистрибутивной множественностью, может выступать в качестве фактора, «дислокализирующего» во времени действия (процессы, события) комплексной ситуации высказываний. В случае множественности объектных или субъектных актантов действий в приведенных выше высказываниях актуализируются таксисные значения дистрибутивной одновременности нелокализованных во времени действий.

(2) темпорально-аспектуально-таксисные (темпоральные, аспектуальные и/или таксисные) маркеры или экспликаторы временной локализованности действий, указывающие на точное время протекания или осуществления действий (процессов, событий) или их протяженность во времени (длительность/дуративность) в комплексной ситуации высказываний: (а) темпоральные и аспектуальные адвербиалы jetzt, morgen, gestern, vor kurzem, längst, lange, in nächster Woche, im nächsten Jahr, in zwei Jahren, im Jahre 1989, im September, im Winter, am Tage, am Abend, am Mittwoch um 9 Uhr, am Freitag, am 7. September vor dem Treffen и др.; (б) таксисные адвербиалы gleich, sofort, unmittelbar, dann, darauf, danach; (в) комплексные (комбинированные) таксисно-темпоральные адвербиалы spätestens am Tage nach dem Eintreffen, gleich am Tag unserer Abreise, unmittelbar nach dem Treffen am Abend, gleich nach diesem Treffen um 19 Uhr и др. 
В состав полипропозитивных высказываний, актуализирующих аспектуально-таксисные значения одновременности и разновременности локализованных во времени действий могут входить следующие маркеры или экспликаторы (моно-, би- или поликомпонентные):

а) темпоральные (morgen, jetzt, heute, gestern, bald, in nächster Zukunft, im nächsten Monat, in nächster Woche, im nächsten Jahr);

б) аспектуальные с семантикой длительности (lang, lange, kurz) или фазовости (endlich, schließlich);

в) таксисные, ориентирующие, как правило, на контактное следование или частичную одновременность действий в комплексной ситуации высказываний (gleich, zeitgleich, direkt, sofort, unmittelbar, dann, danach, darauf).

В качестве мономаркеров могут выступать отдельные темпоральные, аспектуальные или таксисные наречия, входящие в общую семантическую структуру высказывания: Bei seiner Rückkehr ist der Fischotter heute nicht allein [22].

Бикомпонентные маркеры (темпоральные, аспектуальные, таксисные) входят в состав предложно-девербативных конструкций с предлогами bei, mit, während, nach, vor, seit, bis и др. и содержат темпоральную лексику (наречия, имена существительные и прилагательные темпоральной семантики. Например:

Unmittelbar nach dem Treffen war der erste Termin für eine Arbeitssitzung der Kommission [22].

Am Samstagmittag vor der Abreise nach Köln war er der einzige Keeper im Abschlusstraining der Grün-Weißen [22].

Bei diesem Treffen im Frühjahr wird stets das Motto des Fellbacher Herbstes bekannt gegeben [22].

Das Treffen erfolgt nur einen Tag nach einer Zusammenkunft des Präsidenten der Afrikanischen Kommission [22].

Gleich nach der Ankunft brachen sie zu einer gemeinsamen Erkundung des Strandes auf [22].

В состав поликомпонентных (комбинированных) темпорально-аспектуально-таксисных маркеров, выражаемых предложными девербативами в сочетании с другими семантическими компонентами, входят темпоральные, аспектуальные, таксисные адвербиалы (наречия времени, длительности, кратности, фазовости, одновременности и др.), «календарные» имена существительные, а также темпоральные и аспектуальные прилагательные или причастия (der Tag, der Abend, der Morgen, der Nachmittag, der Mittag, der Samstagsmittag, die Woche, die Stunde, der Montag, der Mittwoch, der Winter, das Jahr, das Frühjahr, bald, morgig, jetzig, gestrig, zweitägig, wenig, kurz, lang, endlich, abschließend). Например:

Die leeren Transportgefäße schickt man unverzüglich, spätestens am Tage nach dem Eintreffen, an den Absender als Frachtgut «leer zurück!» und frachtfrei, wenn man die Leihgebühr sparen will [23].

Noch wenige Stunden vor dem Eintreffen der Gäste wuselten die Handwerker durch die neuen Räume [22].

Mit dieser Zusammenkunft der EU-Regierungschefs, die am Mittwoch um 9 Uhr beginnt, bricht eine neue Ära an [22].

Darauf haben sich die Gemeinden Monschau und Bütgenbach am Freitag bei einem gemeinsamen Treffen verständigt [22].

Der österreichische Außenminister Dr. Bruno Kreisky nahm laut Wiener Zeitung am 7. September vor dem Treffen der Auslandsösterreicher in Wien zur Frage einer Losung des Südtirolproblems Stellung [23].

Темпоральные маркеры различного компонентного состава (моно-, би- и поликомпонентные), как правило, участвуют в языковой репрезентации аспектуально-таксисных значений одновременности и разновременности локализованных во времени действий с «точным» указанием времени их осуществления или протекания.

(3) локальные маркеры, эксплицирующие пространственное (локальное или темпорально-локальное расположение локализованных во времени действий (при комбинации с темпоральными, аспектуальными или таксисными маркерами). Например:

Nach einem Treffen mit Petraeus am Montag in New York twitterte Trump, er sei sehr beeindruckt von ihm [22].

Klaus sagte dies nach seinem Treffen mit Napolitano am Dienstag in Rom [22].

Die Ankündigung aus Wien kommt kurz vor dem zweitägigen Treffen der europäischen Innen- und Justizminister im estnischen Tallinn [22].

Nach der Abreise Mikojans blieb der Stellvertretende Vorsitzende des Staatlichen Komitees für Außenwirtschaftsbeziehungen, V.A. Sergejew, noch einige Tage in Delhi [23].

Локальные или темпорально-локальные маркеры как элементы синтагматического таксисного контекста участвуют в актуализации аспектуально-таксисных значений одновременности или разновременности локализованных во времени действий и процессов, указывая на их конкретное локальное (пространственное) (in New York, im estnischen Tallinn, in Delhi, in Wien) или локальнотемпоральное расположение (am Dienstag in Rom, am 7. September vor dem Treffen in Wien).

(4) итеративные маркеры: итеративные атрибуты в составе предложных девербативов (jeder, jedesmalig, mehrfach, mehrmalig) и итеративные адвербиалы цикличности, кратности, счетного комплекса, узуальности, интервала действия и др. (wieder, wiederum, sonntags, stets, 
morgens, abends, nachts, sonnabends, freitags, mehrmalig, mehrmals, häufig, zweimal, gewöhnlich, anchmal, oft, meist, meistens, dreimal täglich, zweimal monatlich, meistens morgens, täglich zwei Stunden и др.) [3; 6; 9; 16; 17]. Например:

Katja hatte ihr damals nicht geglaubt und Friedel bei jedem Treffen mißtrauisch beobachtet [23].

Bei jedem unserer Zusammentreffen diskutierten wir auf Augenhöhe über wichtige Angelegenheiten [22].

Eines Tages führte Herr O. entgegen der bis dahin geübten Praxis das Aufstehen der Prozeßbeteiligten bei jedem Erscheinen des Gerichts ein [23].

Er dirigiert deshalb meist im Sitzen [22].

Семантика итеративных адвербиалов в синтагматическом таксисном контексте эксплицирует итеративнотаксисные значения одновременности или разновременности нелокализованных во времени действий или процессов (ср. следующие высказывания: (1a) с семантикой временной нелокализованности итеративных (повторяющихся) действий и (16) с семантикой временной локализованности при наличии темпорального маркера jetzt: (1a) Er dirigiert meist im Sitzen. (16) Er dirigiert jetzt im Sitzen.).

(5) лексическая и аспектуальная семантика глаголов (в частности, перфективных (терминативных, предельных), итеративных или фазовых (ингрессивных, эгрессивных, а также с семантикой продолжения действия) с экспликацией начальной, срединной или конечной фазы действия (beginnen, anfangen, starten, anbrechen, losbrechen, ausbrechen, einsetzen, fortsetzen, fortfahren, fortführen, weiterführen, weitermachen, dauern, enden, beenden, aufhören и др.). Например:

Nach dem Ausscheiden aus dem Arbeitsleben beginnt eine neue Lebensphase [22].

Bald nach seiner Ankunft in Theresienstadt begannen die Dreharbeiten [22].

Zeitgleich mit dem Eintreffen des Baumes startete der Aufbau der Hütten für den beliebten Markt [22].

В приведенных выше высказываниях с фазовыми глаголами репрезентируются фазово-таксисные значения частичной одновременности и строгого (дистантного) следования локализованных во времени конкретных действий (см. семантику ингрессивности в высказываниях с глаголами starten, beginnen и эгрессивности в высказывании с глаголом beenden). При актуализации аспектуально-таксисной семантики строгого (дистантного) следования или предшествования соотносимые между собой действия характеризуются «временной делимитацией», т. е. отграниченностью контуров «индивидуальных внутренних времен» $[19$, с. 36]. Длительность интервала между «индивидуальным внутренним временем» соотносимых между собой действий эксплицируется с помощью аспектуальных маркеров (атрибутов, адвербиалов) с семантикой длительности или протяженности во времени (lang, kurz, kürzer, länger, tagelang, wochenlan, monatelang). Ср. также:

Kurz vor ihrem Treffen mit der Spitze des Zentralrats der Muslime schlägt die AfD-Vorsitzende Frauke Petry scharfe Töne an [22].

Mark Zuckerberg schaffte es nach tagelangem Schweigen gerade mal, ein paar magere Zeilen zu posten [22].

Таксисные значения дистрибутивной одновременности и разновременности нелокализованных во времени действий могут быть актуализированы при наличии дистрибутивных глаголов (диверсативов, цислокативов и др.) и множественности субъектных или объектных актантов: Sie ging dann neben ihm her, zog eifrig die Brauen im Nachdenken zusammen und fragte ... [23]. В высказываниях с глаголом pflegen с семантикой «иметь обыкновение делать что-либо» актуализируется итеративное значение узитативности (повторения «в соответствии с эмпирически наблюдаемой вероятностной закономерностью») [17, с. 174] нелокализованных во времени повторяющихся действий: Auf dem Fussboden lag ein ausgebleichter Teppich, und nur dort, wo der Mann während des Speisens zu sitzen pflegte, war ein neurer, kleinerer mit blühenden Farben gelegt (H. Fallada).

Итак, в силу межкатегориального взаимодействия категории таксиса и категории временной локализованности/нелокализованности в соответствующем поликатегориальном семантическом комплексе в высказываниях с предложными девербативами актуализируются сопряженные темпорально-, итеративно-, фазово-таксисные категориальные ситуации одновременности и разновременности локализованных или нелокализованных во времени действий (процессов, событий) при множественности конкретных субъектов/объектов действий и наличии темпоральных, аспектуальных, итеративных, локальных и др. маркеров. Наличие в семантической структуре анализируемых высказываний темпоральных, аспектуальных, итеративных, таксисных или локальных маркеров подтверждает факт тесного интегративного взаимодействия категории таксиса с категорией ВЛ/ВНЛ, а также с функционально-семантическими категориями темпоральности и аспектуальности. 


\section{ЛИТЕРАТУРА}

1. Агапитова А.А. Временная локализованность высказывания в немецком языке. Автореф. дис. ... канд. филолог. наук. СПб., 2005. 19 с.

2. Архипова И.В. Высказывание с предложными девербативами в современном немецком языке: монография. Новосибирск: НГПУ, 2012.148 с.

3. Архипова И.В. Кратный таксис в современном немецком языке // Вестник Новосибирского государственного педагогического университета. 2013 . № 6 (16). C.149-159.

4. Архипова И.В. Предложный девербатив как конституент зависимого таксиса современного немецкого языка // Вестник Новосибирского государственного педагогического университета. 2016. № 4. С. 135-142.

5. Архипова И.В. Категория таксиса в лингвистике (на материале немецких высказываний с предложными девербативами) // Вестник Новосибирского государственного педагогического университета. 2017. № 4. С. 196-205.

6. Архипова И.В. Функционирование девербативов в итеративно-таксисной категориальной ситуации // Мир науки, культуры, образования. 2019. № 6 (79). C. 564-565.

7. Архипова И.В. Функционально-семантическая категория таксиса в отечественной лингвистике // Евразийский гуманитарный журнал. 2019. № 4 (1). C. 59-66.

8. Архипова И.В. Модель функционально-семантического поля таксиса // Современная наука: актуальные проблемы теории и практики. Серия: Гуманитарные науки. 2020. № 1. С. 131-137.

9. Архипова И.В. Таксис и итеративность: межкатегориальное взаимодействие// Современная наука: актуальные проблемы теории и практики. Серия: Гуманитарные науки. 2020. № 4. С. 112-116.

10. Архипова И.В. Предложные девербативы в темпорально-аспектуально-таксисной категориальной ситуации // Мир науки, культуры, образования. 2020. № 4. C. 503-504.

11. Байтувганова И.Д. Категория временной локализованности действия в кумыкском языке. Автореф. дис. ... канд. филолог. наук. Махачкала, 2010.22 с.

12. Бондарко А.В. Общая характеристика семантики и структуры поля таксиса // Теория функциональной грамматики: Введение, аспектуальность, временная локализованность, таксис. Изд.6-е. М.: Книжный дом «Либроком», 2011. С. 234-242.

13. Бондарко А.В. Категоризация в системе грамматики. М.: Языки славянских культур, 2011а. 488с.

14. Бондарко А.В. Временная локализованность // Теория функциональной грамматики: Введение, аспектуальность, временная локализованность, таксис. Изд.7-е. М.: ЛЕНАНД, 2017. С.210-233.

15. Бондарко А.В. Глагольные категории в системе функциональной грамматики. 2-е изд. М.: Издательский дом ЯСК: Языки славянской культуры, 2017а. $336 \mathrm{c}$.

16. Комиссарова Е.С. Итеративные адвербиальные единицы в функционально-семантическом аспекте. Автореф. дис. ... канд. филолог. Наук. Пермь, 2014. 24 c.

17. Кибардина С.М. Выражение множественности действий в немецком языке // Типология итеративных конструкций / Отв. ред. В.С. Храковский. Л.: Наука, 1989. С. 170-179.

18. Лепшоков Х.С. Типы временной нелокализованности действия: На материале карачаево-балкарского и русского языков. Автореф. дис. ... канд. филолог. наук. Карачаевск, 2011. 24 с.

19. Полянский С.М. Основы функционально-семантического анализа категории таксиса (на материале немецкого языка): Учебное пособие к спецкурсу. Новосибирск: Изд-во НГПИ, 1990. 90 с.

20. Смирнов И.Н. Категория временной локализованности/нелокализованности действия и ее взаимодействие с темпоральностью и аспектуальностью // Известия Российского государственного педагогического университета им. А.И. Герцена. 2010. № 126. С. 186-194.

21. Смирнов И.Н. Признак временной локализованности/нелокализованности действия в аспектуальной семантике русского глагола // Сибирский филологический журнал. 2011. № 2. С. 172-180.

22. Лаборатория корпусной лингвистики Лейпцигского университета (LC). URL: http://www.wortschatz.uni-leipzig.de (дата 0бращения: 14.08. 2020).

23. Немецкий корпус (Dwds). URL: http://www.dwds.de (дата обращения: 14.08.2020).

$$
\text { (C) Архипова Ирина Викторовна (irarch@уandex.ru). }
$$

